\title{
O PANÓPTISMO E OS DISCURSOS DAS PROFESSORAS EM UMA INSTITUIÇÃO ESCOLAR DO CÁRCERE NA FRONTEIRA
}

\author{
THE PANOPTISMO AND THE SPEECHES OF TEACHERS IN A SCHOOL INSTITUTION OF CÁRCERE IN THE \\ FRONTIER \\ EL PANÓPTICO Y LOS DISCURSOS DE LAS PROFESORAS EN UNA INSTITUCIÓN ESCOLAR DEL CÁRCÉN EN LA \\ FRONTERAL
}

\author{
BARCELOS, Clayton da Silva ${ }^{1}$ \\ NOGUEIRA, Cinthia Caldeira ${ }^{2}$ \\ OSÓRIO, Antônio Carlos do Nascimento ${ }^{3}$
}

\section{RESUMO}

Este artigo parte de estudos realizados no período de 2015 e 2017 e teve como propósito, a partir do Panóptismo de Bentham (1793), compreender as práticas das professoras que atuam na escolarização de internos do sistema penitenciário. O objetivo foi analisar a arquitetura escolar da prisão de um município fronteiriço e suas implicações pedagógicas. Foi utilizada a etnografia e a análise do discurso das professoras atuantes. Os resultados evidenciam a discrepância quanto ao ambiente de aprendizagem prisional em um mesmo município, bem como os reflexos da docilização que o panóptismo traz aos sujeitos, alunos (as) e professoras, se distanciando muitas vezes de suas finalidades e propósitos.

Palavras-chave: Educação em prisão. Panóptico. Arquitetura prisional. Professoras na prisão.

\section{ABSTRACT}

This article is based on studies carried out in the period of 2015 and 2017 and has as its purpose from the Panoptism of Bentham (1793) to understand the practices of teachers who work in the schooling of inmates of the penitentiary system. The objective was to analyze the school architecture of the prison of a frontier municipality and its pedagogical implications. It was used the ethnography and the analysis of the discourse of the working teachers. The results evidenced the discrepancy regarding the prison learning environment in the same municipality, as well as the reflexes of the docilization that the panopticism brings to the subjects, students and teachers, often distancing themselves from their purposes and purposes.

Keywords: Education in prison. Panopticon. Prison architecture. Teachers in prison.

\section{RESUMEN}

Este artículo parte de estudios realizados en el período de 2015 y 2017 y tuvo como propósito a partir del Panoptismo de Bentham (1793) comprender las prácticas de las profesoras que actúan en la escolarización de internos del sistema penitenciario. Objetivo fue analizar la arquitectura escolar de la prisión de un municipio fronterizo y sus implicaciones pedagógicas. Se utilizó, la etnografía y el análisis del discurso de las profesoras actuantes. Los resultados evidencian la discrepancia en cuanto al ambiente de aprendizaje prisional en un mismo municipio, así como los reflejos de la docilización que el panoptismo trae a los sujetos, alumnos y profesoras, distanciándose muchas veces de sus finalidades y, propósitos.

Palabras clave: Educación en prisión. Panóptico. Arquitectura prisional. Profesoras en la prisión.

\footnotetext{
1 Universidade Federal do Mato Grosso do Sul - UFMS - Campo Grande - Mato Grosso do Sul - Brasil

2 Universidade Federal do Mato Grosso do Sul - UFMS - Campo Grande - Mato Grosso do Sul - Brasil

${ }^{3}$ Universidade Federal do Mato Grosso do Sul - UFMS - Campo Grande - Mato Grosso do Sul - Brasil
} 


\section{INTRODUÇÃO}

Para compreender o local que se desenvolveu o estudo para escrita deste artigo, se faz necessário entender o panóptismo concebido por Jeremy Bentham (século XVIII) como um mecanismo aplicável ao controle do comportamento dos prisioneiros nas prisões e para tal, compreender o sistema penitenciário sul-mato-grossense que, na atualidade, tem o seu gerenciamento sob responsabilidade da Agência Estadual do Sistema Penitenciário de Mato Grosso do Sul (Agepen/MS), que coordena a administração de 44 estabelecimentos prisionais estaduais.

Os dados do último Levantamento Nacional de Informações Penitenciária (Infopen) ${ }^{4}$, de junho de 2016, indicam uma realidade transcrita em números de $726.712^{5}$ pessoas privadas de liberdade, em que o estado de Mato Grosso do Sul lidera com a maior taxa de encarceramento do País, perfazendo uma população de 697,7 pessoas presas para cada grupo de 100 mil habitantes em todo o estado.

A Agepen/MS administra um patronato penitenciário e quatro Unidades Penais (UPs) no município de Corumbá, localizado a $420 \mathrm{~km}$ da capital do estado, na fronteira com a Bolívia.

Três dessas UPs possuem salas de aula e oportunizam educação básica aos custodiados sendo o "Estabelecimento Penal de Corumbá" (EPC), UP de segurança média destinada a presos condenados do sexo masculino que cumprem pena no regime fechado; o "Estabelecimento Penal de Regime Semiaberto, Aberto e Assistência ao Albergado de Corumbá" (EPRSAAAC), UP de segurança mínima destinada a presos condenados do sexo masculino que cumprem pena no regime semiaberto e aberto; e o "Estabelecimento Penal Feminino Carlos Alberto Jonas Giordano" (EPFCAJG), UP de segurança média destinada a presos condenados do sexo feminino que cumprem pena no regime fechado.

Vale ressaltar que dentro do EPFCAJG também funciona, como uma espécie de anexo, o semiaberto feminino, porém segundo informação da coordenação local, não existe educação escolar devido ao pequeno número de mulheres privadas de liberdade, além da possibilidade de liberação pelo Juiz da Vara de Execução Penal para que elas frequentem aulas fora do cárcere.

Nascida na fronteira por necessidade estratégica relacionada à Guerra do Paraguai, considerado como o maior conflito internacional ocorrido na América do Sul (1864-1870) travada entre o Paraguai e a Tríplice Aliança (Brasil, Argentina e Uruguai), o município de Corumbá se alicerça pela forte presença dos diversos setores das forças armadas nacional, tanto o exército quanto a marinha, que se instalaram na região pantaneira para proteger seus limites com os países vizinhos.

Depois de 1870, o poder público ergueu no município de Ladário ${ }^{6}$ a Base Naval da Marinha trazendo um grande número de militares, operários e uma volumosa tropa de diferentes regiões do

${ }^{4} \mathrm{O}$ Infopen é um sistema de informações estatísticas do sistema penitenciário brasileiro, atualizado pelos gestores dos estabelecimentos desde 2004 que sintetiza informações sobre os estabelecimentos penais e a população prisional.

${ }^{5}$ Para este cálculo, não foram contabilizadas as pessoas em prisão albergue domiciliar e as centrais de monitoração eletrônica.

${ }^{6}$ Município sul-mato-grossense localizado a apenas $6 \mathrm{~km}$ do centro de Corumbá, integrando-se social e economicamente com o município objeto de estudo. 
País, em especial oriunda do estado do Rio de Janeiro, que permanecem na região até os dias atuais contribuindo ainda mais para a diversidade social, cultural e econômica local.

Tendo como fio condutor o Grupo de Estudos e de Investigação Acadêmica nos Referenciais Foucaultianos (GEIARF) vinculado a Linha de Pesquisa Educação, Cultura, Sociedade, do Programa de Pós-graduação em Educação da UFMS (PPGEdu/UFMS), a qual os autores desse estudo se dedicam, e os predicados do tema introduzido acima, realizamos como abordagem de investigação científica do tipo de pesquisa qualitativa, empregando em seus procedimentos a técnica etnografia como suporte técnico ao referencial metodológico, mas com menor permanência no campo de pesquisa.

Somou-se às técnicas do parágrafo anterior, entrevistas semiestruturadas na construção de subsídios que possibilitassem compreender as dinâmicas e as especificidades de uma escola no cárcere de um município fronteiriço, marcado por uma trajetória de conflitos. Enquanto uma das etapas do estudo, a pesquisa de campo foi realizada no ambiente escolar do sistema penitenciário do município de Corumbá/MS, que segundo Gonsalves (2001, p.67)

[...] é o tipo de pesquisa que pretende buscar a informação diretamente com a população pesquisada. Ela exige do pesquisador um encontro mais direto. Nesse caso, o pesquisador precisa ir ao espaço onde o fenômeno ocorre, ou ocorreu e reunir um conjunto de informações a serem documentadas.

Ao percorremos o caminho da pesquisa tipo etnográfica, seguimos as orientações de Lüdke e André (1986), que fazem uma abordagem sobre o campo em educação como uma das vertentes qualitativas. De acordo com as referidas autoras, etnografia "é a descrição de um sistema de significados culturais de um determinado grupo" (LÜDKE E ANDRÉ, 1986, p. 13).

O etnógrafo encontra-se, assim, diante de diferentes formas de interpretações da vida, de compreensão do senso comum, de significados variados atribuídos pelos participantes às suas experiências e vivências (ANDRÉ, 2015). Procurando mostrar ao leitor esses significados múltiplos extraídos das entrevistas realizadas com as professoras envolvidas.

Além disto, a abordagem do tipo etnográfica, segundo Lüdke e André (1986), permite a combinação de diferentes técnicas de pesquisa como a observação, a entrevista e a análise de documentos. Por isso, neste estudo, pudemos contemplar entrevistas para recolher mais informações e levantar dados que sejam inacessíveis a uma simples visita. Sobre pesquisa participante ensina Gil (2010):

O pesquisador que se dispõe a realizar uma pesquisa etnográfica assume uma visão holística com vistas a obter a descrição mais ampla possível do grupo pesquisado. A descrição pode incluir múltiplos aspectos da vida do grupo e requerer considerações e ordem histórica, política, econômica, religiosa e ambiental. Os dados obtidos, por sua vez, precisam ser colocados numa perspectiva bem ampla para que assumam significado. Por outro lado, é preciso garantir que os resultados da pesquisa privilegiem a perspectiva dos membros do grupo investigado. (p. 127). 
As entrevistas têm a finalidade de aprofundar as questões e esclarecer os problemas observados. Sendo assim, foram utilizadas entrevistas semiestruturadas, pois como ensinam Barros \& Lehfeld (2000, p.58) e Trivinos (1987, p.146), elas estabelecem uma conversa amigável com o entrevistado e buscam levantar dados que possam ser utilizados em análise qualitativa, como uma ferramenta, selecionando os aspectos mais relevantes de um problema de pesquisa.

Levando em consideração o formato da entrevista semiestruturada, a subjetividade inerente a cada entrevistado, bem como os dados etnográficos construídos, foi necessário ter atenção aos processos de constituição do sujeito entrevistado e suas possíveis relações com a verdade, pois, indiscutivelmente, são representações de poderes e de saberes que se alinham em relação com o outro (entrevistado) e consigo mesmo (pesquisador), entendendo que o sujeito traz consigo muito mais que o discurso que produz, mas também a forma que compreende a realidade que se insere e as percepções que elabora de uma construção quase que inesgotável (SANTOS; OSÓRIO, 2015).

Cabe mencionar, que todas as professoras que atuam na estrutura educacional das prisões do estado são contratadas ${ }^{7}$, não tendo nenhuma que pertença ao quadro permanente da Secretaria de Estado de Educação (SED/MS) ou outro órgão público. Esses profissionais recebem uma gratificação, devido ao local de trabalho compreendido como de risco ou insalubre, o valor de $50 \%$ a mais do salário praticado aos professores das redes de ensino que atuam em escolas que não estejam dentro de UPs.

No município de Corumbá, são $15^{8}$ as professoras que atuam nas atividades de escolarização e se revezam nas aulas entre as três UPs, sendo que 14 são do sexo feminino e apenas 1 do sexo masculino. Estes profissionais, bem como todos os demais que atuam nas instituições escolares dentro dos presídios do estado, estão lotados na "Escola Estadual Polo Professora Regina Lúcia Anffe Nunes Betine", localizada no município de Campo Grande.

A Escola Betine funciona como pólo e suas salas de aula são pulverizadas nas UPs da capital e nos municípios do interior do estado, englobando estabelecimentos prisionais masculinos e femininos, de regime fechado, semiaberto e aberto, e são consideradas como "[...] o lugar onde a aprendizagem acontece e de acordo com a disponibilidade de espaço físico e da demanda de cada Unidade Prisional é que se estabelecerão salas de onde funcionarão uma ou mais de uma fase", assim como determina o Projeto Político e Pedagógico (PPP, 2014, p. 18).

\footnotetext{
${ }^{7}$ Fonte: Informação da direção da Escola Polo Betine.

${ }^{8}$ Os nomes utilizados são fictícios, visando manter o anonimato das professoras entrevistadas. Entre as interlocutoras apenas um professor era do sexo masculino e utilizar um nome fictício masculino para ele o identificaria da mesma forma. Assim, buscando manter o sigilo e anonimato da pesquisa optou-se pela utilização de nomes femininos e comuns aos dois gêneros, garantindo o sigilo na identificação das pessoas e seu gênero.
} 


\section{OS ESPAÇOS EMPÍRICOS: ENCONTROS E DESENCONTROS}

As entrevistadas externaram se identificar com a educação escolar em ambiente de privação de liberdade, até mesmo aquelas com apenas cinco meses de experiência disseram que as especificidades do ambiente educacional em prisão não geraram nenhum desconforto ou obstáculo, pelo contrário, eram motivações para continuar o labor e aprendizagem. Todas as convidadas a participar da pesquisa aceitaram ser entrevistadas de imediato e contar sobre suas experiências.

Embora as visitas ao município de Corumbá tenham ocorrido no período de 2015 a 2017 optamos pelo tempo verbal presente para que a forma textual seja mais clara traduzindo de maneira fidedigna a observação dos locais de estudo. Cada estabelecimento penal do município de Corumbá conta com duas salas de aula, onde as professoras se revezam na docência para um total de 82 alunos (dados do ano de 2016) matriculados na modalidade de Educação de Jovens e Adultos (EJA), conforme informação disponibilizada pela coordenação pedagógica local.

As salas são divididas em níveis de Ensino Fundamental e de Ensino Médio, buscando facilitar o trabalho das professoras em meio aos alunos e seus diferentes graus de conhecimento, sendo caracterizadas como enturmação.

No regime fechado (masculino e feminino) EPC e EPFCAJG as aulas ocorrem nos períodos matutino e vespertino. No regime semiaberto (masculino) EPRSAAAC acontecem apenas no período noturno, uma vez que durante o dia os alunos deste regime não ficam aprisionados e são liberados para o trabalho extramuros, benefício concedido pelo Juiz da Vara de Execução Penal ao privado de liberdade que cumpre pena no regime semiaberto, que consiste em sua saída para o trabalho, com uma média de 8 horas diárias retornando ao fim do expediente para uma rápida rotina de banho, jantar e sala de aula.

Os estabelecimentos de regime fechado, masculino e feminino, ficam um ao lado do outro bem próximos à rodovia que dá acesso a capital do estado, Campo Grande. Distante deles, cerca de $5 \mathrm{~km}$, está o EPRSAAAC.

Durante as visitas e realização das entrevistas foi possível fazer observações separadas de cada estabelecimento, identificando suas particularidades onde fizemos os registros das datas em que ocorreram antes de suas descrições. São excertos dos discursos produzidos pelas professoras entrevistadas. A letra "P" em maiúsculo nos diálogos significa pesquisador e os nomes atribuídos são fictícios, assim transcritos.

\section{MASCULINO DE REGIME SEMIABERTO}

A primeira UP visitada foi o EPRSAAAC, que fica na periferia do município, sendo seu acesso por ruas não pavimentadas. A estrutura do prédio chama atenção. Tudo muito antigo e em péssimas 
condições de conservação, adaptado, improvisado e meio que remendado, uma espécie de "puxadinho" para todos os lados.

Isso se deve, segundo informações levantadas durante as entrevistas, pois o prédio abrigava um prostíbulo antes de ser destinado ao presídio, o que explica sua adaptação e o grande número de torres em toda fachada. A portaria se localiza em um local que no passado abrigou uma piscina e outro espaço destinado à sauna.

Ao adentrar o local nos deparamos com uma passarela inicialmente com piso de paralelepípedo que logo foi substituída apenas por chão batido. À esquerda um muro lateral, bem próximo à passarela, já a direita um grande descampado com árvores e diversos automóveis sucateados, espaço que no passado era uma área destinada ao estacionamento de carros dos clientes do prostíbulo que se chamava "Boate da Cris".

Essa passarela possui uma extensão de mais ou menos 50 metros, sendo o acesso todo descoberto, escuro e ermo no período noturno (horário em que ocorrem as aulas), o que nos fez imaginar que pudesse dificultar, consideravelmente, o acesso em dias de chuva, sendo esse empecilho corroborado por uma das entrevistadas.

O local destinado às salas de aula fica ao fundo das instalações do imóvel. Sobre esse espaço, a professora falou durante a entrevista realizada no dia 9 de junho de 2016, assim transcrita:

\section{P: E o acesso à sala de aula é só por aqui?}

Darcy: Só.

$P$ : Não tem um acesso coberto?

Darcy: Não.

$P:$ E já teve situação de não ter aula porque chove?

Darcy: Uhum, já!

Além de uma estrutura aquém da necessária para um ambiente escolar, o que por si só já é um problema, a fala da professora revela os desdobramentos desta falta de estrutura, quando afirma que em algum momento não teve aulas devido a chuva.

Chegando ao ambiente escolar, constata-se que o mesmo é formado por duas salas de aula e um banheiro em condições precárias, beirando a impossibilidade de uso, uma pequena varanda improvisada, com cercamento feito de grades de tamanhos e formatos diferentes, colocadas aleatoriamente, juntamente com telas utilizadas para cercamento de animais e que não agradava aos olhos, além de ser coberta com telhas furadas do tipo "eternit", que retém fortemente o calor do sol, provocando um ambiente com temperaturas elevadas. 
Nesta varanda, há uma mesa retangular em madeira do tipo utilizada em cozinhas de residências e um bebedouro de inox para refrigerar água. Para chegar ao local o trajeto se dá pela lateral da carceragem, porém sem acesso visual daqueles que estão em suas celas e tampouco dos agentes penitenciários.

Durante as aulas apenas o professor permanece em sala com os alunos, enquanto os agentes penitenciários se encontram na portaria da UP e no corredor da carceragem. O agente apenas comparece ao recinto quando está próximo do horário final da aula, para acelerar o recolhimento dos alunos em suas celas. Este ambiente escolar, não supervisionado pelo agente penitenciário de forma constante, retrata o que Michel Foucault (2014) apresenta como o "efeito mais importante do panóptico":

Г...1 induzir no detento um estado consciente e nermanente de visibilidade aue asseaura o funcionamento automático do noder. Fazer com đue a viđilância seia nermanente em seus efeitos. mesmo se é descontínua em sua acão: que a perfeicão do poder tenda a tornar inútil a atualidade de seı exercício: Г . l 1 enfim. aue os detentos se encontrem nresos numa situacão de boder de aue eles mesmos são bortadores. Para isso. é ao mesmo temno excessivo e muito pouco aue o prisioneiro seia observado sem cessar bor um viaia: muito bouco. Dois o essencial é aue ele se saiba vigiado; excessivo, porque ele não tem necessidade de sê-lo efetivamente. (p.195).

O próprio corpo (sujeito-subjetividade) passa a ser, paulatinamente, um edifício esquadrinhado, onde cada espaço subjetivo (comportamentos, desejos, pensamentos) é controlado e governado, sistematicamente, por uma consciência diretora que foi internalizada pelo sujeito em seu processo de socialização.

As salas de aula têm pintura antiga e manchada, forro em madeira com vários pontos de infiltrações e buracos, o chão é de qualidade ruim, dois ventiladores quebrados e um ar-condicionado (insuficiente) para atender as duas salas, formando um ambiente de aprendizagem precária. Sobre a entrevista, realizada no dia 10 de junho de 2016, destaca-se:

P: Bacana. Se tivesse alguma coisa que você pudesse melhorar, o que você melhoraria?

Samira: O prédio, a iluminação, material que eu pudesse trazer mais. Eu já consegui na escola, consegui doação de livros, vou trazer, mas eu fico pensando porque quando chove aqui a sala enche de água. Aí você fica triste porque não tem material, não tem caderno, aí você tem que correr atrás. Eu corro muito atrás, eu não tenho vergonha de pedir não, eu sou pidona mesmo. 
Da fala da professora é possível extrair que ela não tem vergonha em pedir materiais aos seus alunos, tanto que se adjetiva como "pidona", visando melhorar as condições do ambiente escolar que não é das melhores, pois segundo ela existe muito o que melhorar no espaço físico destinado a escola.

O espaço que atualmente atende a educação escolar no passado abrigava uma cozinha externa, onde as profissionais que trabalhavam na boate faziam suas refeições. Era um local restrito, não sendo acessível aos clientes do antigo estabelecimento. Essa inacessibilidade permanece enquanto ambiente escolar prisional, uma vez que a presença dos agentes penitenciários não é constante ficando a cargo do professor a responsabilidade sobre a sua segurança naquele local.

O ambiente de salas de aula, visivelmente adaptadas, são dotadas de lousa verde (arranhadas e desbotadas) de tamanhos muito pequenos, divididas por painéis de madeira compensada, (utilizado como tapumes em obras de construção civil) com uma passagem de uma sala para outra.

A divisão não chega até a altura do forro, o que faz com que a confusão de sons entre as salas seja intensa, já que em cada sala tem uma professora por turma, com uma estrutura precária, conforme se depreende no fragmento da professora entrevistada a seguir (transcrição da entrevista realizada no dia 09 de junho de 2016), que assim menciona ao ser questionada:

P: (...) e num contexto geral sobre a educação dentro do sistema prisional como que você avalia, Darcy?

Darcy: Eu acho que faltaria um pouco mais de recurso, pra montar projetos pelas salas de aula daqui porque quando chove não tem aula não tem condições de ter aula (...) cai muita água, muitas vezes estraga material. Quando eu cheguei foram muitos livros jogados fora aqui.

Mais uma vez aparece no discurso de uma professora a falta de estrutura física do espaço destinado a educação escolar, identificando a falta de recursos para montar projetos e os problemas que aparecem junto com as chuvas, incluindo a perda de livros e suspensão de aulas.

A iluminação é boa nas duas salas, que ficam ao lado da fossa que armazena todos os dejetos da UP. O cheiro é muito forte e ruim, a estrutura é péssima, as carteiras, de diversos modelos, ficam espalhadas pela sala o que torna sua disposição desorganizada, além do ambiente ser sujo e empoeirado, conforme fragmento da entrevista realizada no dia 9 de junho de 2016 quando a professora informa ao ser indagada:

\section{P: O que você vê como necessidade específica dos alunos daqui?}

Juracy: Bom, o lugar em si já fala. Não é uma sala de aula muito atrativa, o clima que você vê lá dentro... por exemplo, aqui na minha sala tem uma janela e do lado de fora tem uma fossa. Então tem dias que você chega que o 
cheiro é insuportável, você não consegue dar aula, é um cheiro assim, horrível. Isso vai desgastando a pessoa [...].

Juracy: Não tem condições de ter aula. Não tem como, tá aquele cheiro da fossa não tem como ninguém prestar atenção por mais prazerosa que seja a aula, não dá.

Somado aos problemas de falta de estrutura já relatados pelas outras professoras, Juracy acrescenta a problemática da fossa existente ao lado da sala de aula o que faz com que o mau cheiro adentre o local e cause desgaste a todos já que os alunos não conseguem prestar atenção na aula, por mais prazerosa que seja.

\section{FEMININO DE REGIME FECHADO}

A segunda UP visitada foi o EPFCAJG (regime fechado), que fica cerca de $5 \mathrm{~km}$ distante do EPRSAAAC. O acesso é todo por vias pavimentadas. Logo na fachada foi possível perceber que as instalações foram construídas para ser uma UP.

Não havia nada que indicasse qualquer tipo de adaptação, pelo contrário, o prédio é todo circulado por uma muralha alta com passarelas para vigilância onde se encontrava um policial militar armado. Outra realidade estrutural se revelou durante a visita, completamente diferente da primeira UP visitada.

Tal estrutura é compreensível pelo tipo de regime instituído no local. O regime fechado tem como prioridade a segurança e para tal requer controle e vigilância constante. Muito embora as estruturas físicas das UPs, tanto a de regime fechado como a de semiaberto, visitadas possam não corresponder a proposição de Bentham com seu modelo arquitetônico construído em forma de anel, com uma torre ao centro para que o indivíduo seja vigiado de forma constante pela contraluz, a dinâmica social e os processos de subjetivação transladaram esse panóptico para a subjetividade dos sujeitos. Ele tornou-se um dispositivo de dispersão dos mecanismos disciplinares promovendo afetos e a sensação perene de que há vigilância.

Antes de chegar ao espaço destinado às atividades de escolarização, passamos a entrada principal do prédio, pela parte interna do estabelecimento e percorremos alguns metros pelo corredor central, que se continuasse a percorrê-lo, alguns metros adiante, daria acesso aos pavilhões ${ }^{9}$. A sensação de organização e segurança foram fortes o que é confirmado na fala, da entrevista realizada no dia 10 de junho de 2016 pela professora:

\footnotetext{
${ }^{9}$ Local onde estão situadas as celas e solários. Solário é o espaço físico parecido com uma jaula, normalmente com grades sobre o teto, que oportunizam a entrada de sol. É onde o banho de sol dos encarcerados é realizado. A Lei de Execução Penal (LEP) prevê direito a saída da cela a todo preso por 2 horas diárias.
} 
Ivanir: Entendeu? E aqui, dentro no prisional, nós temos mais segurança do que lá fora... porque aqui eles não podem fazer nada respeitam mais, né... lá fora não... a gente não pode revistar um aluno, não sabe o que o aluno tá trazendo a sala de aula, tanto é que temos casos... noticiários que alunos agridem professores... diretores, né... agora eu me sinto mais segura do que lá fora

\title{
P: Você nunca teve problema com violência aqui?
}

Ivanir: Não.

$P:$ Não?

Ivanir: Não.

$P$ : Nunca foi xingada?

Ivanir: Nem discussão.

É possível perceber na fala da professora sua sensação de segurança em trabalhar em uma escola dentro do presídio quando comparada a uma escola de fora do cárcere, afirmando nunca ter sofrido violência ou xingamento. A justificativa é a segurança e o respeito inerente ao ambiente prisional, o que inclui a possibilidade de revista pessoal nos alunos e a disciplina imposta. Sobre esta FOUCAULT a diferenciou como:

\begin{abstract}
A "disciplina" não pode se identificar com uma instituição nem com um aparelho; ele é um tipo de poder, uma modalidade para exercê-lo, que comporta todo um conjunto de instrumentos, de técnicas, de procedimentos, de níveis de aplicação, de alvos; ela é uma "física" ou uma "anatomia" do poder, uma tecnologia. E pode ficar a cargo seja de instituições "especializadas" (as penitenciárias, ou as casas de correção do século XIX), seja de instituições que dela se servem como instrumento essencial para um fim determinado (as casas de educação, os hospitais). (2014, p.208).
\end{abstract}

A educação dentro do sistema penitenciário é uma aliada do corpo de segurança de uma UP. Aquele que frequenta a instituição escolar dentro da instituição prisional é disciplinado duas vezes, facilitando o trabalho do professor e do agente. Quem frequenta as aulas não quer perder a oportunidade de remição, por este motivo se mantém sobre o poder da disciplina, visto que a qualquer ato que venha a ser compreendido como indisciplina ficará suspenso de frequentar as aulas, logo, sem remir.

Chegando ao local destinado às aulas nota-se que o espaço é exclusivo para essa finalidade e fica próximo à área destinada a administração da UP. Logo no início do corredor, que dá acesso aos pavilhões e celas, já se encontra o espaço para as atividades de educação escolar, o que faz com que 
os barulhos provenientes dos solários, durante o banho de sol, não atrapalhem as atividades docentes e discentes.

O espaço, assim como a UP, é todo pintado nas cores da Agepen/MS (amarelo e preto), sem pichações, de aspecto novo, limpo e com boa conservação, embora a estrutura por si só não garanta que as aulas atinjam seus objetivos como diz a professora Francis, na entrevista realizada no dia 18 de novembro de 2016 quando responde:

P: Entendi. Qual que é maior dificuldade da professora em se trabalhar dentro do presídio?

Francis: Para mim é a metodologia. Porque, por exemplo, lá para minha matéria é difícil. Então no você entrar com materiais... os tipos de materiais que você pode utilizar lá dentro são mais restritos. Então assim, você tem que rebolar para poder conseguir levar uma aula produtiva para eles, por conta dessas restrições de material que você pode utilizar.

P: E você acha que essas restrições são necessárias mesmo ou existe um exagero do corpo de segurança?

Francis: De certa parte isso é um exagero, porque... falo assim, muitas vezes são produtos, são ingredientes que você vai utilizar que não requer risco nenhum. Então... e eles nesse sentido.

P: Se você pudesse, professora... o quê que você melhoraria no seu trabalho?

Francis: Então, o que eu gostaria de fazer mais era justamente essas aulas mais experimentais, de ter essa possibilidade de fazer mais aulas experimentais. Eu acho que ali ainda faltam um pouco de recursos para metodologia. Por exemplo, ali quase não se usa... no caso, a gente quase não usa os computadores, quase não se usa os materiais tecnológicos para poder colocar uma... para fazer com que uma aula seja bem melhor desenvolvida hoje, ele está... ele deixa a pessoa mais interessada, que eu acho que isso falta pouco, acho que isso seria melhor.

Francis vê a limitação imposta pelo corpo de segurança a entrada de certos materiais para aula com um certo exagero. Relata ainda que a utilização de outros recursos metodológicos, como computadores, também é diminuída, o que faz com que as aulas não se tornem tão interessante.

As instalações contam, além das duas salas de aula, com bebedouro (dispondo de água gelada), dois banheiros, uma ampla sala para atividades diversas (como cursos de pintura em tela e 
em parede, bordado, hidráulica, entre outros) e uma biblioteca partilhada com a sala dos professores e de informática, com cinco computadores em bom estado de conservação e com acesso à internet.

A estrutura é climatizada, contando ainda com uma servidora penitenciária da área de segurança e custódia como apoio (disponível durante todo o período de aulas na sala da biblioteca) para o que for necessário, visando, segundo a diretora da UP, um melhor aproveitamento das aulas.

O espaço é todo interligado por cabos de rede de internet com kit multimídia, notebook, microfone, projetores e caixa de som, além de inúmeros mapas geográficos de parede e mesa, espalhados pelo ambiente; violões para atividades culturais; carteiras novas, limpas, alinhadas e organizadas. O que se percebe no ambiente escolar desta UP é uma estrutura boa e superior à estrutura encontrada na UP visitada anteriormente, assim como aquelas das escolas de fora da prisão.

\section{MASCULINO DE REGIME FECHADO}

O terceiro estabelecimento visitado foi o EPC (masculino de regime fechado). A UP fica ao lado do EPFCAJG e suas portarias ficam separadas por menos de 30 metros. Entre uma unidade e outra tendo apenas o local destinado à equipe da polícia militar, que faz a guarda da muralha das duas UPs. A estrutura é bastante semelhante com a do EPFCAJG, porém mais robusta, visivelmente, com maior preocupação com a segurança.

Ao sair da portaria, para adentrar ao local, é necessário percorrer o trajeto de passar por duas grades/portões de proteção, caminhar por alguns metros em linha reta em um caminho todo calçado, mas sem cobertura, até chegar ao prédio principal da UP. Bem a frente, percebe-se um tapume com brasão da Agepen/MS, uma espécie de biombo, para disfarçar a entrada do pavilhão, que fica exatamente naquele local.

$\mathrm{Na}$ lateral deste biombo existe um corredor que dá acesso à sala dos serviços de apoio psicológico. Ao deixar a sala do apoio e seguir pela parte exterior do prédio é possível encontrar, facilmente, as salas de aula, mas antes de atingi-las, a imagem da sagrada família desenhada na parede nos chama atenção.

Durante todo trabalho etnográfico foram apenas estas duas figuras, que não são discretas nem pequenas separadas por menos de 10 metros uma da outra e ambas nesta UP, que se desvelaram. São duas imagens ícones no contexto prisional.

Um brasão, por ser o símbolo da Agepen/MS, que de forma indireta é carregada da militarização do estado, e a sagrada família, revelando a forte influência cristã de uma sociedade frente à limitação de um estado em sua laicidade. Importante destacar que a etnografia revelou que as duas figuras foram pintadas por privados de liberdade da mesma UP.

Caminhando um pouco mais, para além da figura da sagrada família, chegamos ao local reservado a educação escolar, que além das duas salas de aula, conta com uma terceira sala, dividida em dois ambientes, sendo: uma sala de professores, com ar-condicionado, armários, mesas, 
computadores, telefone e todo mobiliário e objetos necessários para o fim a que se destina e uma biblioteca.

O ambiente, que também possui um banheiro destinado aos alunos, é pintado de cor clara, arejado e com ventiladores. O local é acessível aos alunos durante todo período de aulas, mas com necessidades de melhorias aos olhos das professoras, o que pode ser observado na entrevista realizada em 18 de novembro de 2016:

P: Entendi. Se você pudesse, professora, o que você melhoraria no seu trabalho?

\section{Santana: Meu trabalho?}

$P: E$, naquele contexto prisional todo, para o seu trabalho ser um pouco melhor? O que falta para melhorar, ser melhor do que é?

Santana: Eu... assim, eu sinto muita falta de algumas coisas técnicas assim. Por exemplo, data show, poderia mexer mais com outras coisas que a gente não pode levar, mais filme. Assim, coisas pequenas. Por exemplo, em outras escolas... na escola pública você vai numa sala de tecnologia, eles não têm isso ainda. Igual a educação física, eles não saem fora. Então essas coisinhas eu acho que seria bom para eles.

\section{P: Você se sente realizada com o seu trabalho?}

Santana: Sim. Eu acho que eu fiquei muito mais realizada lá dentro do que eu estava aqui fora. Quando eu sai do outro emprego, eu trabalhava com educação infantil, primeiros anos então foi muito desgastante. Para mim era mais alívio entrar na prisão dar aula, me sentia mais realizada lá do que aqui fora.

Repete na fala da professora Santana a necessidade de utilização de outros recursos metodológicos, citando como exemplo a falta de data show. A professora também relata a impossibilidade de levar outros materiais e lamenta ser proibido apresentar filmes aos alunos, mas apesar das limitações mencionadas, ela revela sentir-se realizada e aliviada em dar aula na prisão, pois fora é muito desgastante.

As professoras aguardam seus horários para entrar em sala de aula na biblioteca. Durante toda a tarde existe um rodízio entre elas, local onde ocorre os encontros e o bate papo. Foi neste local que foram realizadas as entrevistas e as observação de nosso estudo.

Os alunos permaneceram o tempo todo em sala de aula sob os cuidados da professora que lá se encontrava. Eventualmente, um transitava pela biblioteca, pois era caminho para o banheiro por eles 
utilizado, mas a sensação de segurança naquele ambiente era forte, o que se destaca da entrevista realizada no dia 18 do mês de novembro de 2016:

\title{
P: Entendi. E você, que já deu aula fora do sistema prisional, se sente mais
} segura dando aula lá fora ou aqui dentro?

Julian: Esse é um ponto que até mesmo os alunos questionam, me perguntaram esses tempos atrás... "professora, é mais tranquilo dar aula aqui do que fora não é verdade, professora?" e por vezes é o que acontece porque, fora o aluno ele... você está sujeita a inúmeras situações. Aqui não, porque eles já sabem o requisito que eles têm que seguir, né? Eles comentam que não é permitido tais coisas, então aqui a gente já se sente mais segura realmente.

Novamente a sensação de segurança maior na escola que está dentro do ambiente prisional em relação a escola que está fora aparece na fala das professoras. Julian atribui tal sensação ao fato dos alunos saberem a forma que devem agir dentro da prisão. Forma de agir que, embora não apareça na fala da professora, está intimamente ligada a disciplina do ambiente e a remição de pena pelo estudo.

Sobre remição De Maeyer (2013) em estudo anterior já identificou que

\begin{abstract}
A problemática da oferta e da procura em educação dos jovens e adultos no cárcere é complexa. Há alguns anos, verificamos que, em geral, a maioria dos jovens e adultos que buscavam se inserir em algum programa educacional ou educativo no cárcere eram aqueles que já tinham um nível de educação elevado - por vezes muito elevado. (...)

É assim que vimos os detentos que possuíam o nível de educação de base se inscreverem em cursos de alfabetização, porque ainda havia lugar e porque as horas e dias passados em classe eram considerados na concessão de eventuais remição ou na avaliação do comportamento. (p. 36-37).
\end{abstract}

Na biblioteca, os livros organizados nas prateleiras são de responsabilidade de um privado de liberdade que, além de organizar o espaço, fica encarregado dos empréstimos e recolhimento dos livros aos demais que não estudam. Todas as sextas-feiras ele passa com o carrinho de livros no pavilhão e os internos que têm interesse ficam com o livro durante uma semana.

$\mathrm{Na}$ sexta-feira seguinte ele faz a mesma rotina de empréstimos ou recolhimento de livros. Assim como no EPFCAJG, os livros que aparecem nas prateleiras são oriundos de doações e contemplam em sua maioria enciclopédias e doutrinas jurídicas. Nesta UP as salas de aula foram adaptadas para tal finalidade, com uma boa disposição, possuindo carteiras em bom estado de conservação em um ambiente organizado. 
Com iluminação adequada, aparelho de ar-condicionado e ventiladores nas duas salas e uma lousa branca, o ambiente foi apontado como deficiente pela professora Ariel, na entrevista do dia 18 de novembro de 2016), em que ela informa após ser indagada:

\section{P: Entendi. Quais as maiores dificuldades de trabalhar dentro do sistema?}

Ariel: É a falta de estrutura, é a maior das grandes dificuldades. Olha só, nós não temos ar condicionado na sala de aula. Onde você vai ficar numa sala de aula onde é um bando de homem... Quente, sem ar. Não tem condição. Os alunos trazem ventilador de dentro da cela para aqui para dentro. Você está me entendendo? Para você ver. E eles são tão bons que eles jogam o ventilador tudo em cima de mim. Eu falo para eles, "não, pelo amor de Deus".

P: E o que você acha que o seu trabalho, mesmo com essa dificuldade...

Ariel: Olha só, nós não temos computador, nós não temos internet, gente. Olha aí, tudo só enfeite. Eu falo para vocês, podia ter um cabo de internet aí você trabalhando. Olha, como eu (não) tenho aula agora à tarde, poderia fazer o que agora à tarde? Poderia está planejando uma aula diferenciada ou fazendo aula diferente nesses intervalos. Eu tenho que trabalhar com livro, eu não poderia procurar algo de criativo para eles, entendeu? Atual ou algo que eu possa diferenciar com eles. Não tem essa aparelhagem.

P: E mesmo com essas dificuldades, que são grandes que a gente vê, você acha que vocês conseguem atingir o objetivo de ressocializar, de ensinar minimamente dentro do que você se propõe?

Ariel: $100 \%$ ? Não.

A falta de possibilidade de utilização de outros recursos, como computadores parece ser algo constante na fala das professoras. Ariel relata o problema do calor, devido a falta de ar condicionado, além da impossibilidade do uso de computadores e da ausência da internet, o que faz com que as professoras não otimizem seu tempo e não avancem tanto em suas aulas.

Foi observado, como ponto negativo, o fato do espaço destinado à educação escolar não ser exclusivo para esse intuito, onde as portas das salas de aula ficam em um corredor de acesso externo ao pavilhão seguro ${ }^{10}$ do presídio, ocasionando um trânsito constante de agentes penitenciários,

\footnotetext{
${ }^{10}$ Recebe esse nome, pois habitam nesse pavilhão apenas os privados de liberdade que têm problemas com a "massa carcerária" e sofrem risco de vida. $\mathrm{O}$ acesso é feito por corredor externo justamente para uma maior segurança dos que ali estão. Em caso de motim ou rebelião, essa população está separada do restante, o que pode facilitar a evacuação e ser determinante em manter ou não a vida dessas pessoas. Pavilhão formado quase que em sua totalidade por estupradores, travestis, viciados, devedores de dinheiro a outros privados de liberdade e aqueles que praticaram furtos dentro da prisão.
} 
privados de liberdade, professoras, alunos, além de um contínuo e desconfortável barulho e um contato direto das professoras com ações da segurança e custódia.

"Dito de outra forma, a área de segurança e custódia é aquela que desenvolve a atividade mais temida dentro do ambiente prisional, que é o aprisionar, vigiar e libertar a pessoa presa, ficar na linha de frente de todo sistema" (BARCELOS, 2017, p. 394).

Essa mistura entre a segurança e educação aparece na fala da professora Lucimar, em entrevista realizada no dia 10 de junho de 2016, em que:

P: Quando a gente fala em segurança e educação, dentro do sistema prisional, você acha que um se sobreponha ao outro? Um tem mais valor do que o outro? Um tem mais atenção do que o outro?

Lucimar: É a segurança. Ela é sempre. Acho que vem em primeiro, né! Em relação a educação dentro do estabelecimento, até mesmo por parte da Agepen, dos agentes... Acho que é a segurança que vem em primeiro lugar aqui.

A fala da professora desvela uma tensão existente no ambiente prisional, entre a segurança e educação. O corpo de segurança coloca seus objetivos sempre a frente da educação oferecida no cárcere o que faz com que os professores, inconscientemente, reconheçam que o trabalho desempenhado pelo corpo de segurança se sobrepõe à tarefa da educação escolar, ignorando assim a responsabilidade educativa dos agentes penitenciários (BARCELOS, 2017).

A constatação é de que as professoras, com menos tempo de contratação (atuação na educação escolar na prisão), desenvolvem seu labor na UP com as piores condições de trabalho, ao passo que as professoras mais antigas, desempenham suas atividades no espaço da UP com melhores condições de trabalho.

Esse tema não apareceu de forma declarada na fala das professoras durante as entrevistas, apenas na etnografia. Das 15 professoras entrevistadas, dois terços, ou seja, 10 servidoras foram contratadas no ano de 2016 e, destas 10, metade dão aulas no estabelecimento penal masculino de regime semiaberto, aquele que estruturalmente se mostra com o pior espaço para educação escolar.

Das 05 professoras mais antigas (de 04 a 13 anos atuando como professoras dentro dos presídios), 04 delas atuam no EPFCAJG, aquele que tem as melhores condições de estrutura física, destacado na entrevista realizada em 10 de junho de 2016, que quando perguntada...

\section{P: Hoje a senhora está só aqui?}

Cleomar: Trabalho só aqui... tenho mais de dez anos que trabalho só aqui. 


\section{P: Só aqui? A senhora trabalha em quais unidades?}

Cleomar: Só aqui mesmo, só no feminino. Já trabalhei lá no semiaberto. $A$ gente passa por vários processos.

P: Como que a senhora vê seu papel dentro desse sistema penitenciário? E a educação?

Cleomar: É bem importante pra mim como pessoa, como educadora. Aqui a gente vive várias experiencias, né? O crescimento é meu e dos alunos.

A professora, com mais experiência na educação escolar na prisão, concentra toda sua carga horária apenas no EPFCAJG, 03 delas dividem as cargas horárias entre o EPFCAJG e o EPC e apenas uma delas dá aula no EPRSAAAC, aquele com piores condições estruturais, na fala das próprias professoras. As aulas são atribuídas, primeiramente, às professoras com mais tempo (experiência) de aulas no sistema penitenciário, posteriormente, as professoras mais novas são lotadas nas UPs em horários abertos (sobrantes).

\section{CONSIDERAÇÕES}

Diante desse trabalho etnográfico as possibilidades de problematização se amplificam nas mais variadas temáticas, porém iremos nos ater a duas, o que não significa que são as principais ou mais importantes, apenas as que titularam mais atenção, concomitantemente, para os pesquisadores envolvidos neste estudo.

A primeira, relaciona-se a teoria panóptica que embora tenha se tornado popular graças a Michel Foucault (1975), o conceito panóptico foi concebido por Jeremy Bentham (XVII) como um mecanismo aplicável ao controle do comportamento dos prisioneiros nas prisões, que explicita em uma maneira de estrutura arquitetônica projetada para cárceres e prisões, incluindo os espaços de escolarização, o que foi detalhado pelas entrevistas realizadas com as professoras que atuam nas atividades pedagógicas, além das observações analíticas empíricas realizadas pelos pesquisadores durante as visitas ao campo de estudos.

É um arranjo circulante ou dentro de uma ortopedia de um ponto central de circulação e divisão de espaços possíveis, podendo controlar o comportamento de todos os reclusos em escolarização, micro ou ainda macro, determinando condições precárias a que se submetem, porém nunca poderiam estar cientes de que estavam sendo observados ou não.

O prisioneiro(a) poderá ser monitorado a cada momento, tendo que controlar seu comportamento para não ser punido. A teoria panóptica de Michel Foucault, a ideia do panóptico que vê a sociedade de hoje, é um reflexo desse sistema (sujeição). 
Para este autor, a passagem do tempo nos fez mergulhar em uma sociedade disciplinar, que controla o comportamento de seus membros através da imposição de vigilância, que não se atem a uma especificidade institucional, no caso as UPS.

O poder procura atuar através da vigilância, controle e correção do comportamento e do pensamento. Um poder de impor comportamentos em toda a população com base na ideia de que estamos sendo observados entre desvios ou premiando-se bom comportamento (remição), o que aparece latente durante as entrevistas por outros discursos, inclusive documentais.

Foucault (1975) diz que o panóptico expressa muito bem o tipo de domínio que ocorre na era contemporânea: os mecanismos de vigilância são introduzidos em corpos, fazem parte de um tipo de violência que se articula através das expectativas e significados que transmitem os espaços e as instituições, no caso prisional, se agrava pela precariedade estrutural que são submetidos, ao novo esquema de exclusão.

A segunda, diz respeito ao fato das professoras sentirem segurança para ministrar aula dentro dos estabelecimentos penais. Ao adentrar o sistema penitenciário, como custodiado, o sujeito que cumpre sua pena não tem mais o controle de si, como narrou Foucault nos anos 70 "[...] assim, quem prende alguém não o pune; controla-o" (FOUCAULT, 2015, p.62).

A prisão isola, controla e seleciona parte da população que se desviou da conduta dita como correta e as próprias professoras não dão atenção aos possíveis perigos sobre os quais estariam submetidas em sala de aula, embora afirmem que estão "seguras". É um novo dispositivo de sujeição, em que os perigos não são a priori previstos, somente quando se manifestam.

O controle não se dá apenas na limitação do ir e vir, é imposto dentro das UPs na tratativa entre agentes penitenciários e custodiados e, se revela ainda mais na busca pela remição. Os sujeitos envolvidos devem ser dóceis, independentemente de serem professores ou privados de liberdade, pois o que se encontra no ambiente escolar passa constantemente pelo processo de disciplinamento da outra instituição (prisão).

Os dados do Infopen traçam um perfil ${ }^{11}$ da massa carcerária de maioria sem acesso e permanência a educação básica, antes do encarceramento, tornando inquietante a reflexão sobre a oferta da educação, direito fundamental previsto na Constituição Federal, e sobre a fala das professoras sobre as dificuldades no ensino em sala de aula. Tal reflexão nos leva a questionar o tipo de oferta de um ensino de "qualidade" dentro daquele ambiente restrito que, pelas suas finalidades, não trabalha pelo princípio de acesso ao conhecimento, tão pouco consegue instituir a dita ressocialização.

Mas como ofertar educação dentro de uma penitenciária? Osório (2004) apresenta um breve relato sobre a história da educação no Brasil onde conta o fato desta não ter sido prioridade deste o período Colônia e salienta que até o currículo é tratado de forma disciplinadora como "grade" e não

${ }^{11} \mathrm{O}$ Infopen traçou o perfil predominante que recai sobre a população prisional brasileira relacionando raça, idade e escolaridade, sendo 64\% de maioria negra, 55\% em uma faixa etária de 18 a 29 anos e 51\% com ensino fundamental incompleto. 
"matriz curricular". O autor traz ainda a indagação sobre a escola pensada institucionalmente, cuja função não é o ensino e sim a vigilância.

Essa mesma instituição que exclui da sociedade o sujeito transgressor é a que insere os mecanismos de inclusão de regresso deste a sociedade. Tal estrutura não difere da realidade extramuros, uma sociedade que se organiza pela exclusão, que nunca foi e nunca será só econômica, mas acima de tudo, pelas práticas sociais operacionalizadas por uma cultura de seleção, discriminatória e preconceituosa.

\section{REFERÊNCIAS}

1. ANDRÉ, Marli Eliza Dalmazo Afonso de. Etnografia da prática escolar.Campinas: ePub. PDF, 13 de setembro de 2015.

2. BARCELOS, Clayton da Silva. Educação escolar na prisão: os significados e sentidos das professoras que atuam em unidades penais de Corumbá, Mato Grosso do Sul. 167f. Dissertação (Mestrado em Educação) Universidade Federal de Mato Grosso do Sul, Corumbá, MS, 2017.

3. BARCELOS, Clayton da Silva. Sobre o direito de ter/dar aulas na prisão: um relato de experiência sobre segurança, direito e educação. Revista Cocar, v. 11 n. 21 jan./jun. 2017. p. 391-411. Disponível em: <https://paginas.uepa.br/seer/index.php/cocar/article/view/1299/816>. Acesso em: 03/08/2018.

4. BARROS, Aidil de Jesus Paes de. LEHFELD, Neide Aparecida de Souza. Projeto de pesquisa: propostas metodológicas. Petrópolis, RJ: Vozes, 2000.

5. BENTHAM, Jeremy (1995). The Panoptic Writings. [S.I.: s.n.].

6. BRASIL, Ministério da Justiça. Levantamento Nacional de Informações Penitenciárias (INFOPEN). Departamento Penitenciário Nacional. Brasília, DF. 2016.

7. DENZIN, N. K. e LINCOLN, Y. S. (orgs). O Planejamento da pesquisa qualitativa: teorias e abordagens; tradução Sandra Regina Netz. Porto Alegre: Artmed, 2005.

8. FOUCAULT, M. A sociedade punitiva: curso no Collège de Frence (1972-1973); Tradução Ivone C. Benedetti. - São Paulo: Editora WMT Martins Fontes, 2015.

9. FOUCAULT, M. Vigiar e punir: Nascimento da prisão. Editora Vozes, São Paulo. 2014. 
11. GONSALVES, Elisa Pereira. Iniciação à pesquisa científica. Campinas, SP: Alínea, 2001.

12. LÜDKE, Menga e ANDRÉ, Marli Eliza Dalmazano Afonso de. Pesquisa em educação: abordagens qualitativas. São Paulo: EPU, 1986.

13. MATO GROSSO DO SUL. Projeto Político Pedagógico. Secretaria de Estado de Educação. E. E. Polo Profa. Regina Lúcia Anffe Nunes Betine. Campo Grande/MS. 2014.

14. SANTOS, M. W. B.; OSÓRIO, A. C. N. Os ogros são como cebolas: diferentes ofertas de subjetivação presentes na personagem Shrek. Pro-Posições (Unicamp), v. 28, p. 169-192, 2017.

15. TRIVINOS, Augusto Nibaldo Silva. Introdução à pesquisa em ciências sociais: a pesquisa qualitativa em educação. São Paulo: Atlas, 1987.

16. OSÓRIO. A.C.N.; OSÓRIO, A.M.C. O Direito a educação: os desafios da diversidade social. Revista do Centro de Educação (UFSM), n² 24, p.1-9, 2004.

\section{Clayton da Silva Barcelos}

Professor Assistente da Universidade Federal do Oeste da Bahia - UFOB. Doutorando e Mestre em Educação pela Universidade Federal de Mato Grosso do Sul - UFMS. Especialista e Bacharel em Direito pela UFMS.

\section{Cinthia Caldeira Nogueira}

Mestranda em Educação pela Universidade Federal de Mato Grosso do Sul - UFMS. Servidora da Agencia Estadual de Administração do Sistema Penitenciário de Mato Grosso do Sul - AGEPEN/MS.

\section{Antônio Carlos do Nascimento Osório}

Doutor em Educação pela Pontifícia Universidade Católica de São Paulo - PUC/SP. Professor Titular da Universidade Federal de Mato Grosso do Sul - UFMS. Coordenador do Programa de PósGraduação em Educação da UFMS. 


\section{Como citar este documento:}

BARCELOS, Clayton da Silva; OSÓRIO, Antônio Carlos do Nascimento; NOGUEIRA, Cinthia Caldeira. O panóptismo e os discursos das professoras em uma instituição escolar do cárcere na fronteira. Reflexão e Ação, Santa Cruz do Sul, v. 27, n. 2, abr. 2019. ISSN 1982-9949. Disponível em: $<$ https://online.unisc.br/seer/index.php/reflex/article/view/12622>. Acesso em: 2019. doi:https://doi.org/10.17058/rea.v27i2.12622. 